\title{
MEMÓRIAS E NARRATIVAS DE IDOSOS: FORMAÇÃO CULTURAL E EXPERIÊNCIA SENSÍVEL NA EDUCAÇÃO
}

\author{
Rita de Cássia Fraga da Costa \\ Silvia Sell Duarte Pillotto ${ }^{2}$ \\ Carla Clauber da Silva ${ }^{3}$
}

\section{INTRODUÇÃO}

A ideia deste artigo é possibilitar a reflexão sobre a formação cultural, que aconteceu em espaços/tempos não formais da educação com um grupo de onze idosos, que frequentavam um Centro Regional de Assistência Social - CRAS. Esta Instituição visa a proteção básica do Sistema Único de Assistência Social (SUAS) nas áreas de vulnerabilidade e risco social. Desenvolvem nesse espaço ações de Proteção de Atenção Integral à Família (PAIF) e o Serviço de Convivência e Fortalecimento de Vínculos (SCFV), no qual a referida pesquisa está vinculada.

O Serviço de Convivência e Fortalecimento de Vínculos organiza seus grupos de atendimento por faixa etária, como: crianças, adolescentes e idosos. A meta é atuar na prevenção de situações de vulnerabilidade e violência, visando por meio da convivência o fortalecimento de vínculos com a comunidade.

Nestas redes de convivência, a pesquisa foi impulsionada por meio de criações artísticas em artesania, trazendo as dimensões éticas e estéticas para o fazer dos próprios sujeitos. As práticas educativas desenvolvidas com o grupo de idosos, aconteceram durante seis semanas consecutivas em encontros de três horas, perfazendo um total de doze horas. Práticas, que mobilizaram as memórias dos idosos, (re)significando suas identidades na medida em que narrativas foram (re)contadas e (re)inventadas. O artesaniar atravessou um percurso constituído de incertezas, de

\footnotetext{
${ }^{1}$ Mestranda em Educação, pela Universidade da Região de Joinville- UNIVILLE, Licenciada em Artes Visuais, 2016 UNIVILLE. Bolsista FAP-UNIVILLE vinculada ao projeto: Educação, experiência e sensibilidade nas práticas educativas - EDUSENPE- PPGE UNIVILLE. E-mail: ritadacosta08@gmail.com

${ }^{2}$ Pós-Doutora no Instituto Estudos da Criança - IEC na Universidade do MINHO - UMINHO, Braga/Portugal em 2007/2008. Professora titular nos cursos de Artes Visuais e Pedagogia na Universidade da Região de Joinville UNIVILLE e no Programa de Pós-Graduação - Mestrado em Educação. E-mail: pillotto0@gmail.com

${ }^{3}$ Possui graduação em Pedagogia pela Associação Catarinense de Ensino (1990), mestrado em Educação pela Universidade do Vale do Itajaí (2003) e doutorado em Doutorado em Educação pela Universidade Estadual de Campinas (2015).E-mail: carlaclauber@hotmail.com
} 
memórias, de criações e sensibilidades, colocando em jogo as subjetividades, que modificavam as práticas educativas e os próprios sujeitos como nos lembra Certeau (1994).

Pensar a artesania pela formação cultural remetemo-nos a Adorno (2010, p. 64) quando sabiamente afirma que a formação cultural "requer amor; e o defeito certamente se refere à capacidade de amar." (ADORNO, 2010, p.64) É por esse caminho que o artigo segue, compreendendo que pesquisar com idosos implica na construção de vínculos afetivos e amorosidade. É preciso, portanto, estar aberto ao mundo, alimentando a potencialidade de se abrir ao desconhecido. E nessa direção, formação cultural significa entender o longo processo histórico, que tem buscado a humanização do sujeito na sensibilidade, corporeidade e racionalidade.

Desta forma, o artigo aqui apresentado estrutura-se nos seguintes itens: "Artesanias: um modo singular de ser/fazer na terceira idade", que tratará dos conceitos de terceira idade e artesania, refletindo sobre os territórios percorridos pelos idosos e a artesania como possibilidade do ser/fazer singular e plural por meio das memórias. Bosi (1994), juntamente com outros autores dá o tom desse item, dialogando com as pesquisadoras e suas experiências. O segundo item a ser tratado "Memórias e narrativas", busca provocar a reflexão sobre práticas educativas com idosos, em que memórias são (re)visitadas, mobilizando experiências sensíveis e novas maneiras de se ver e ver o outro. Aqui a voz está com Certeau (1994) e Benjamin (2010) no diálogo com os demais autores, mas sempre provocando, juntamente com as pesquisadoras, reflexões sobre memórias, que impulsionavam as narrativas. E por fim, o item "Formação Cultural: experiência sensível na educação", busca pensar a formação cultural também como construção identitária, percorrendo caminhos históricos e humanitários em que um conjunto de sentidos e significados vão estruturando a vida do sujeito e de seu grupo social e cultural. Adorno $(2010,2003 ; 1996 ; 1993)$ faz referência a formação cultural, adentrando num universo paradoxo de conflitos e alteridade, destacando a fragilidade humana e sua potência de vida.

$\mathrm{O}$ artigo, faz menção a essas questões, no intuito de provocar a reflexão, especialmente daqueles que atuam na terceira idade, tendo como fio condutor a artesania, pensando nas possibilidades de experiências sensíveis e na formação cultural.

\section{ARTESANIAS: UM MODO SINGULAR DE SER/FAZER NA TERCEIRA IDADE}

O território da velhice, usualmente é visto como um tempo de ausência, quando se é analisado o lugar que ele ocupa na vida em sociedade. Ou ainda, como espaço de esvaziamento da 
vida, entendendo o idoso, como sujeito deste tempo, que muitas vezes sofre no processo de envelhecimento, num declínio lento, intermitente, acompanhado de dolorosa lucidez (BOSI, 1994).

Todavia, o idoso é um ser humano que deve ser respeitado em seu ritmo de vida e em suas singularidades. Precisa de mais tempo para executar certas tarefas e inicia um processo de seleção de suas próprias memórias, apagando as menos importantes. Esse fato é muitas vezes equivocadamente compreendido como perda de memória ou esquecimento. Além disso, como acrescenta Almeida (1998, p.38): "muitas de nossas capacidades dependem de constante exercitação para continuarem vivas e ativas; dependem, acima de tudo, da possibilidade de se alimentarem de projetos, de projetos de vida".

A pesquisa, a partir desses princípios, entende a terceira idade como um valioso tempo de ser, no qual a produção dos saberes e de sensibilidades continuam ativas, possibilitando aos idosos estarem em constante processo de movimento mental e sensível. Para Almeida (1998, p.36) "atingir o território da velhice é defrontar-se com os limites da vida em vida e com a morte em vida".

Se a terceira idade é compreendida como um tempo de ser, o artesaniar é um modo de fazer em que as histórias de vida se (entre)cruzam com o presente, dando novos sentidos e significados a existência humana.

Vale ressaltar que para Petrykowski Peixe et al. (2014, p.41), artesania faz referência "as complexidades e a amplitude, tanto dos processos reflexivos e manuais que envolvem os fazeres artesanais, quanto dos produtos resultantes pelo uso de tais habilidades, nesse caso, o artesanato".

Nesse sentido, o artesaniar é uma ação humana, que lida tanto com as habilidades, como com as culturas em que o artesão está inserido. Portanto, "a produção artesanal é parte da cultura e dos saberes e fazeres locais". (SANTOS ET AL, 2016, p.15) Assim, todo artesanato comunica, pois traz elementos culturais, ambientais, históricos e sociais, permitindo ao consumidor e aos demais interessados em artesania, conhecer, além da história do produto, também o processo de criação do seu produtor.

Artesaniar então pode ser um exercício ou uma ação, que propicia revisitar saberes e conhecimentos, que estão em muitas gerações culturais do passado e do presente. É uma experiência sensível devido à intrínseca necessidade de entrega ao fazer, ao se aventurar (re)significando memórias e sentidos.

No processo de pesquisa, os idosos foram provocados a produzir um Panô coletivo, sem perder de vista a singularidade, pois o primeiro ensaio foi individual. Com as costuras e narrativas 
os idosos foram compondo suas histórias (entre)laçadas em texturas, cores, volumes e movimentos. Uma composição que trouxe no panô seus rastros, suas ausências, seus vazios, seus cheios, seus silêncios e seus cantos.

Nesse sentido, o conhecimento herdado e/ou construído do saber/fazer artesanato, requer preservar a memória e disponibilidade para o exercício constante do fazer e (re)significar aquilo que já se sabe ao longo da vida. O artesão experimenta, ensaia, constrói e (re)constrói uma tradição de saber a partir de um aprender/fazendo, produzindo saberes, e modos de fazer, sempre relacionados ao saber lidar com os recursos humanos e naturais do espaço onde habita (NORONHA, 2016).

Experienciar artesanias, respeitando o contexto cultural dos idosos, é possibilidade de trazer o artesanato como recurso, expressão, linguagem, numa ação geradora de experiência e formação cultural.

Nesse caminho, durante os encontros realizados com o grupo de idosos, planejou-se práticas educativas, com a culminância da criação de um panô coletivo, possibilitando aos idosos (re)visitarem suas memórias articuladas com sua vida presente. Assim, a experiência de artesaniar a vida permitiu aos partícipes da pesquisa e as pesquisadoras acompanhar o pensar e encontrar sentidos num tempo/espaço repleto de sensibilidades.

Logo, o artesaniar adquire amplitude na qual as relações entre o eu e o mundo se modificam, quando o inteligível e o sensível (entre)laçam suas estruturas, agrupando elementos que possibilitam aos sujeitos à percepção, à análise, à pesquisa, entre tantos outros aspectos que compõem os saberes, os fazeres e a construção de conhecimento.

\section{MEMÓRIAS E NARRATIVAS}

As memórias mobilizaram as narrativas dos idosos, que vivenciaram outros modos de fazer, pensar, sentir aquilo que já foi vivido. Nesse processo acontece a conexão do corpo com o tempo, no qual passado e presente são afetados de tal modo que é quase impossível não produzir novos sentidos e percorrer novos caminhos. A memória então, se constitui em costuras feitas em um presente, que faz uma viagem ao passado, trazendo histórias (entre)meadas umas com as outras. Assim, as narrativas ganharam potência no grupo de idosos que artesaniaram suas próprias histórias:

A narrativa, que durante tanto tempo floresceu num meio artesão - no campo, no mar e na cidade - é ela própria, num certo sentido, uma forma artesanal de comunicação. Ela não está interessada em transmitir o "puro em si" da coisa narrada, como uma 
informação ou um relatório. Ela mergulha a coisa na vida do narrador para em seguida retirá-la dele (BENJAMIN, 2012, p. 221).

Ao oportunizar espaço para as memórias e narrativas, buscou-se mobilizar experiências sensíveis, tendo como base para práticas educativas em artesania. Para Meira (2014), as experiências sensíveis são movimentos que exploram os sentidos e assim, o sujeito experimenta a intensidade de todas as formas de percepção. Nesse entendimento, a experiência sensível possibilita um modo ampliado de saber/perceber o mundo de um jeito particular e ao mesmo tempo plural.

É nesse sentido, que a abordagem narrativa como método norteador dessa pesquisa, foi o de potencializar as práticas educativas, sem afastar as sensações, os sentires e as sensibilidades do grupo de idosos e das pesquisadoras. Assim, o percurso metodológico buscou abarcar dinâmicas da vida social e garantir às produções científicas, a participação/intervenção dos pesquisados e pesquisadoras.

Os processos nos múltiplos desdobramentos dos modos de efetuação da vida, se fez presente durante todo o percurso da pesquisa, especialmente nos encontros com idosos, no qual culminou com a produção de um panô coletivo. O panô se constituiu numa peça de tecido criada artesanalmente pelos próprios idosos. Enquanto a peça ganhava força em forma, em imagens e sonoridades, suas memórias ganhavam outras histórias pelas narrativas que se desdobravam em diálogos. Para Certeau (1994, p.158):

a memória é: Instruída por muitos acontecimentos onde circula sem possuí-los (cada um deles é passado, perda de lugar, mas brilho de tempo), ela suputa e prevê também "as vias múltiplas do futuro" combinando as particularidades antecedentes e possíveis. Assim se introduz uma duração na relação de forças, capaz de modificá-la.

Ao movimentar as memórias, imagens e sons são (re)significados, criando outras tantas maneiras de pensar e de sentir. Ao revisitar as memórias é produzido outros sentidos para o que se viveu no passado, ou nas palavras de Halbwachs (2004, p. 76) "é uma imagem engajada em outras imagens." Isso significa que, memória é "uma reconstrução do passado com a ajuda de dados emprestados do presente e, além disso, preparada por outras reconstruções feitas em épocas anteriores e de onde a imagem de outrora manifestou-se já bem alterada" (HALBWACHS, 2004, p. 75-76). 
A imagem e a escuta das narrativas dão ritmo à vida, convertendo o passado num acontecimento do presente. Portanto, a experiência do passado é um modo de (re)organização do pensamento, pois o que está em questão não é a veracidade das histórias, mas sim o sentido que as narrativas provocam nos próprios sujeitos em sua relação consigo mesmo, com o outro e com o mundo.

A memória não é uma ocorrência que chega ao idoso. Pelo contrário, é evocada por ele. É um processo ativo, em que ele procura, até mesmo questiona os outros idosos na busca de confirmar o detalhamento delas. Deste modo, a memória está relacionada com o processo de ontogênese e na definição de uma realidade individuada, num devir que só se resolve em incessante movimento. (BOSI, 1994)

Pela sua trajetória, o idoso (re)constrói com a memória um plano de fundo mais carregado das culturas e relações sociais por onde possa ter vivido. Com isso, apesar da capacidade do idoso em memorizar, estas podem estar acometidas de padrões ideológicos, preconceitos e preferencias, impostos pela sociedade em outros tempos, criando um distanciamento com a atualidade. (BOSI, 1994)

Os idosos, mais do que outros sujeitos, se ocupam longa e atentamente do passado, especialmente pelo percurso percorrido por mais tempo, acolhendo referências de famílias e de culturas. São resultados, construções de memórias, visualizadas em cenários diversos. Então, o que se coloca em destaque é que para o idoso a memória é um processo consciente vinculado a um devir sucessivo de sua individuação, sendo construído ativamente. (BOSI, 1994)

Desta forma, esta pesquisa, especialmente nos encontros com os idosos valorizou os aspectos culturais e identitários, ou seja, é possível afirmar que foi um processo de construção de identidades e formação cultural.

\section{FORMAÇÃO CULTURAL: EXPERIÊNCIA SENSÍVEL NA EDUCAÇÃO}

Nos encontros com os idosos se estabeleceu uma relação de confiança e vínculos afetivos, que foram compartilhados entre eles e as pesquisadoras, uma vez que as narrativas ecoavam, ora evasivas, ora com intensidade, o que corroborava a confiança e a amorosidade que se estabelecia no grupo. Uma convivência na qual reverberou-se diferentes pensares e sentires, o que resultou de um rico repertório cultural, porque os idosos que ali estavam vinham de diversos espaços/tempos, carregados de identidades, que foram se constituindo ao longo do tempo. 
Os repertórios culturais e as construções identitárias estão articulados a ideia de cultura atrelada a cada impulso de compreender uma experiência, do ponto de vista intelectual, ou seja, resultado de um comportamento social (LARAIA, 1986).

Assim, o grupo relacional de idosos, integrantes dessa pesquisa, trouxe consigo uma pluralidade de outros relacionamentos estabelecidos com outros grupos sociais e entendimentos sobre eles. Então, diante de suas construções identitárias, percebe-se como identidade, aquilo que o sujeito reconhece ser diante da família, do grupo, da religião e em toda e qualquer de suas comunidades de relacionamento.

A identidade cultural, portanto, é constituída pelo conjunto de significados que estruturam a vida do sujeito ou de seu grupo social. São identificações, que são construídas nas relações culturais. Nesse sentido, Hall (2006, p.13) afirma que “[...] somos confrontados por uma multiplicidade desconcertante e cambiante de identidades possíveis, com cada uma das quais poderíamos nos identificar - ao menos temporariamente.” Assim, é possível dizer, que no convívio com outras pessoas, outras identidades vão se construindo e se (re)significando nas práticas culturais.

No convívio com os idosos durante a pesquisa, percebeu-se que na liberdade de pensamento e no revisitamento das memórias, a formação cultural pode contribuir como possibilidade de conscientização e subjetividades, em que o sujeito se reconhece como partícipe do processo histórico e cultural em que está inserido. E, por conta disso mobiliza mente e corpo, comprometendo-se com ações mutáveis e contínuas. (ADORNO, 2010)

As práticas educativas, que se conectam a formação cultural, possibilitam a cada um inserir-se em seu processo histórico como sujeito da experiência, em que seu eu singular mistura-se ao seu eu plural. Ou como afirma Adorno (2003), não se pode negar a intrínseca relação entre educação/formação e emancipação, como possibilidade do sujeito sair do seu estado de minoridade a que está submetido para um outro lugar.

Ao longo da história as práticas educativas tiveram e talvez tenham ainda hoje, a incumbência da adaptação do sujeito ao mundo, formando seres ajustados. No entanto, há que se pensar que nesse processo privilegia-se o acúmulo do maior número de informações no menor espaço de tempo em detrimento da qualidade. Adorno (1996, p. 410) sobre essa questão é enfático ao dizer que uma prática educativa "não pode se esquivar da responsabilidade de promover a formação cultural que favoreça o desenvolvimento de uma identidade autocrítica, buscando 
recuperar as potencialidades que, no processo de barbarização humana, ficaram impedidas de se realizar."

Desta forma, a artesania e a arte podem ser o refúgio para pensar o sensível. Adorno (1993) diz que pela arte o sujeito expõe-se em níveis mutáveis de sua autonomia; ao seu outro, dele separado, mas não totalmente. "A arte representa a verdade numa dupla acepção: conserva a imagem do seu objetivo obstruída pela racionalidade e convence o estado de coisas existente de sua irracionalidade, da sua absurdidade.” (ADORNO, 1993, p.68)

E assim a pesquisa também artesaniou pelo universo da arte, da memória, das construções identitárias e de sentidos, constituindo-se em formação cultural. A artesania como um canal de sensibilidades, mobilizou os idosos participantes da pesquisa a (re)conectar-se com suas memórias, podendo assim, restituir ou ampliar novas construções identitárias, ao mesmo tempo em que, puderam revisitar elementos de sua e de outras tantas culturas. Um diálogo sensível que propiciou ao grupo e pesquisadoras sair do seu lugar em busca de outros lugares e de outros saberes.

\section{CONSIDERAÇÕES}

O tempo esteve sempre presente em todos os momentos da pesquisa, indicando pistas significativas. Pode-se constatar que os saberes herdados e/ou construídos pelos idosos no artesaniar, possibilitou o (re)significar aquilo que já se sabia e/ou o que se pensava não saber. Nesse viés, os idosos experimentaram, ensaiaram, narraram e dialogaram com a partir de práticas do aprender/fazendo com o outro.

Ao final dos encontros com os idosos, a artesania ganhou potência nas práticas educativas, uma vez que atravessou a pesquisa, mobilizando memórias e narrativas, que foram (re)significadas no convívio entre eles e as pesquisadoras.

Nesse sentido, os pesquisados tornaram-se sujeitos da pesquisa, partícipes do processo, (re)inventando suas histórias, ampliando seu repertório cultural em um movimento de vozes, escutas e partilhas. Um exercício de disponibilidade para outros movimentos de pensares e sentires em que a memória se tornou um lugar de passagem com visitantes do passado em um tempo presente. A memória então, pode ser entendida como um panô coletivo constituído em costuras de histórias que ganharam novas dimensões sensíveis entre o eu singular e o eu plural. 
Memórias e narrativas, em experiências sensíveis, estiveram presentes em todo o processo de formação cultural, possibilitando a cada um ao seu modo, mergulhar em seus processos históricos e refletir sobre a constituição de suas próprias identidades.

Nesta pesquisa, constatou-se que a formação cultural acontece na liberdade de pensamentos, na relação ética entre pesquisadores e os sujeitos da pesquisa, na relação simétrica na qual rompe-se com a hierarquia entre conhecimento e saberes, entre pensamento e o fazer. A expressão da singularidade ganhou potência, tornando a formação cultural um processo emancipatório.

Espera-se que esse artigo contribua na reflexão da importância de práticas educativas, tendo a artesania e a experiências sensível como pilares na mobilização de um processo legitimo de autonomia e liberdade de pensamento. Os idosos, sujeitos da pesquisa, a partir de suas memórias e histórias narradas, (re)significaram seus pensares e viveres, compreendendo-se como sujeitos históricos e comprometidos com partilha sensíveis de si, do outro e do contexto social.

Esse movimento também impulsionou as pesquisadoras ao revisita mento de suas memórias, traduzidas em tempo/espaço presente/passado, (re)significando suas práticas educativas e de pesquisa. Nesse processo, as pesquisadoras ampliaram, não apenas conhecimentos e saberes, mas sobretudo, suas sensibilidades no que diz respeito ao convívio com o outro e com o entorno, que carrega histórias de vida costuradas as múltiplas identidades de cada sujeito, em cada tempo/espaço e lugar.

\section{REFERÊNCIAS}

ADORNO, Theodor, W. Educação e Emancipação. 5a reimpressão. São Paulo: Paz e Terra, 2010.

ADORNO, Theodor, W. Teoria da Semicultura. Tradução de Newton Ramos-deOliveira. Educação e Sociedade, Revista quadrimestral de Ciência da Educação, Campinas: Editora Papirus, ano 17, n. 56, 1996, p. 388-411.

ADORNO, Theodor, W. \& HORKHEIMER, Max. Dialética do Esclarecimento: fragmentos filosóficos. Trad. Guido Antonio de Almeida. Rio de Janeiro: Jorge Zahar, 1985.

ADORNO, Theodor, W. Teoria Estética. Trad. Artur Morão. Edições 70: Lisboa, Portugal, 1993.

ADORNO, Theodor. A filosofia e os professores. Trad. Wolfgang Leo Maar. In: ed. São Paulo: Paz e Terra, 2003. p. 51-74.

. Educação e emancipação. 3 .

ALMEIDA, V.L.V. Imagens da velhice: o olhar antropológico. Revista A Terceira Idade: São Paulo, SESC, ano X, n.15, dezembro de 1998. p. 35-39.

BENJAMIN, Walter. Magia e técnica, arte e política: ensaios sobre literatura e história da cultura. Tradução de Sérgio Paulo Rouanet. 8. ed. rev. São Paulo: Brasiliense, 2012 (Obras escolhidas, v. 1).

BOSI, Ecléa. Memória e sociedade: lembrança de velhos. 3.ed. São Paulo: Companhia das Letras,1994. 
CERTEAU, Michel de. A invenção do Cotidiano. 1. Artes de Fazer. Tradução de Ephraim Ferreira Alves. Petrópolis: Vozes, 1994.

HALL, Stuart. A identidade cultural na pós-modernidade. 11. ed. Rio de Janeiro: DP\&A Editora, 2006. HALBWACHS, Maurice. A memória coletiva. São Paulo: Centauro, 2004.

LARAIA, Roque de Barros. Cultura: um conceito antropológico. Rio de Janeiro: Zahar,1986.

MEIRA, Marly. O sentido de aprender pelos sentidos. In: PILOTTO, Silvia S. Duarte; BOHN, Letícia Ribas D. (Orgs.). Arte/educação: ensinar e aprender no ensino básico. Joinville: Editora Univille, 2014. p. 53-62.

PETRYKOWSKI PEIXE, Rita I. et al. Projeto Desol na promoção da inovação social de empreendimentos em artesania. In: SIMPÓSIO PARANAENSE DE DESIGN SUSTENTÁVEL, 5º 2014, Universidade Federal do Paraná, Curitiba, Anais do $5^{\circ}$ Simpósio Paranaense de Design Sustentável, 05 de dezembro 2014, p. 41-47.

\section{MEMÓRIAS E NARRATIVAS DE IDOSOS: FORMAÇÃO CULTURAL E EXPERIÊNCIA SENSÍVEL NA EDUCAÇÃO}

\section{Resumo}

O objetivo deste artigo é socializar impressões sobre formação cultural e experiências sensíveis em artesania na terceira idade em espaço não formal da educação. $O$ foco central foi pensar sobre a relevância de práticas educativas pautadas nas construções identitárias e na sensibilidade. A investigação deu-se com um grupo de 11 idosos, entre 60 e 72 anos, integrantes de um Centro de Referência de Assistência Social. Na produção de dados revelou-se que práticas educativas impulsionadas pelas artesanias mobilizam a (res)significação de memórias e narrativas. Além disso, a pesquisa apontou que, ao acessar pela artesania as construções identitárias dos idosos, ocorreu a revitalização dos sentidos.

Palavras-chave: Artesania; narrativas; formação.

\section{MEMORIES AND NARRATIVES OF THE ELDERLY: CULTURAL FORMATION AND SENSITIVE EXPERIENCES IN EDUCATION}

\section{ABSTRACT}

The objective of this article is to socialize impressions about cultural formation and sensitive experiences in crafts in the third age in a non-formal education space. The central focus was to think about the relevance of educational practices based on identity and sensitivity constructions. The research was carried out with a group of eleven elderly people, aged between 60 and 72 years of age and who were members of a Social Assistance Referral Center. During data production, it was revealed that educational practices driven by handcrafts mobilize the (re)signification of memories and narrative. In addition to this, the research showed that upon access through craftsmanship to the identity constructions of the elderly, senses were revitalized.

Key words: Craft; narratives; formation

\section{MEMORIAS Y NARRATIVAS DE ADULTOS MAYORES: FORMACIÓN CULTURAL Y EXPERIENCIA SENSIBLE EN LA EDUCACIÓN}

\section{RESUMEN}

El objetivo de este artículo es socializar impresiones sobre formación cultural y experiencias sensibles en artesanía en la tercera edad en espacio no formal de la educación. El foco central fue pensar sobre la relevancia de prácticas educativas pautadas en las construcciones identitarias y en la sensibilidad. La investigación se dio con un grupo de once adultos mayores, entre 60 y 72 años, integrantes de un Centro de Referencia de la Asistencia Social. En la producción de datos, se reveló que prácticas educativas impulsadas 
por las artesanías, movilizan la (res)significación de memorias y narrativas. Además de eso, la investigación apuntó que, al acceder por la artesanía las construcciones identitarias de los adultos mayores, ocurrió la revitalización de los sentidos.

Palabras clave: Artesania; narrativas; formación 